\title{
DEOXYRIBONUCLEASE IN THE TREATMENT OF PURULENT BRONCHITIS
}

\author{
BY \\ P. C. ElMES* AND J. C. WHITE \\ From the Department of Pathology (Haematology), Postgraduate Medical School of London
}

(RECEIVED FOR PUBliCATION JULY 24, 1953)

In a previous paper Armstrong and White (1950) described studies on purulent bronchial and pleural exudates, showing that extracellular fibres of deoxyribonucleoprotein were responsible for much of their viscidity. Deoxyribonuclease prepared from beef pancreas destroyed these fibres and reduced the viscidity of the exudates both in vitro and in vivo. To determine whether this is of any practical value in the treatment of bronchitis, a controlled experiment was carried out and is reported here.

\section{Selection of Cases}

The sputum of bronchitics is predominantly purulent only during acute episodes of the disease, when bronchial obstruction is the main cause of the symptoms, and of complications such as atelectasis and bronchopneumonia. The course of such exacerbations is very variable and in order to study the response to treatment in sufficient detail only patients admitted to hospital could be used. Of these, many were too ill to cooperate with treatment or tests, and many had had sufficient chemotherapy before admission to convert their sputum from purulent to mucoid. As a result only 23 cases of uncomplicated purulent bronchitis were found suitable in two winters. The patients were observed over a period of 10 days, starting if possible on the day after admission.

\section{Assessment of Progress}

Clinical.-In addition to an assessment of general health a careful history of respiratory illness was taken and the course of the present episode followed with particular reference to these features: (1) Degree of dyspnoea and cyanosis ; (2) degree of systemic venous congestion ; (3) extent and density of added sounds in the chest; (4) the presence of wheezing ; (5) severity of cough; (6) vital capacity; (7) maximal voluntary ventilation.

* Medical Research Council Research Fellow.
The last two were read off spirometer tracings made with a "sanborn" spirometer with a fast moving drum. All these features were recorded on the first, third, seventh and tenth days and the first five on the fifth day also. Treatment was given on the first, third, and fifth days ; the observer did not know which patients received enzyme.

LABORATORY.-Sputum collections were from 9 a.m. to 9 a.m. each day except on the first day, when the sputum produced before the first treatment was kept separate from that produced afterwards. The volume, general appearance, and gross proportions of mucoid and purulent material were recorded. Four smears were made from each specimen, fixed wet with Carnoy's fluid, and stained respectively with pyronin-methyl green mixture (Brachet, 1942), aniline blue and orange G mixture (White, 1950), periodic-acid-Schiff (Hotchkiss, 1946), and Feulgen (Feulgen and Rossenbeck, 1924).

When the volume was sufficient the viscidity of each specimen was measured. The method of Lucas and Henderson (1936) and a method involving the timing of the flow of sputum through a perforated disc under constant pressure proved unsatisfactory because sputum is not homogeneous and has a very wide range of viscidity. Investigation indicates that sputum cannot be treated as a liquid owing to its fibrous structure, and an accurate assessment of its strengh would involve tests unsuitable for routine use (Elmes and White, 1953).

The following simple device gave viscidity as " yield value" readings in arbitrary gram units which covered the range of the material. A $20 \mathrm{ml}$. all-glass syringe was mounted vertically with the occluded nozzle pointing downwards. Both ends of the hollow glass plunger were removed, the upper being left open and the lower being replaced by a perforated brass block (Fig. 1). The sputum was placed in the barrel of the syringe and the plunger forced in until the foamy surface layer and a small amount of the unaerated sputum had flowed through the block. The plunger 


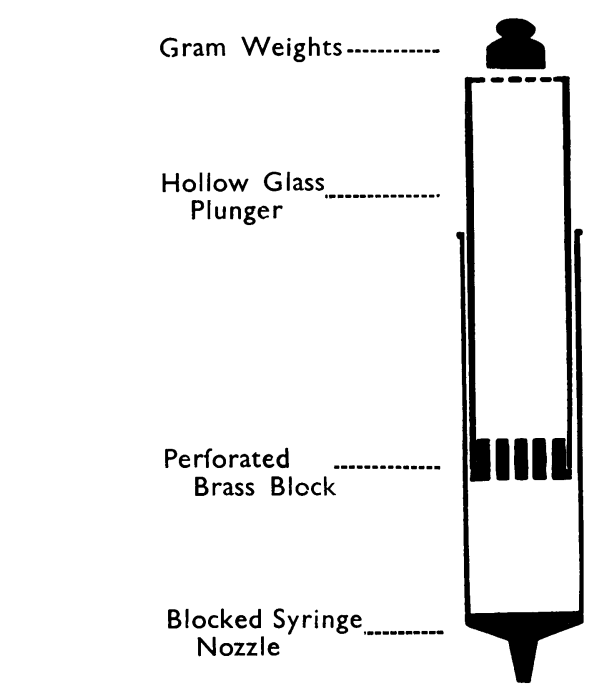

FIG. 1.-Diagrammatic section of a 20-ml. glass syringe adapted to measure the viscidity of sputum.

was not heavy enough by itself to fall through sputum with any significant fibre structure, and weights were placed on top to determine the minimum mass necessary to start the plunger moving downwards. With this device yield values for samples as small as $3 \mathrm{ml}$. were obtained; in larger samples readings were taken at two or three levels in the column.

Examination of the cytochemical preparations was delayed until all the material from all the cases had been collected, to avoid bias in the clinical assessment. The characteristics were recorded under the following headings: (1) Total cellularity, (2) polymorphonuclear leucocytes, (3) mononuclear inflammatory cells, (4) epithelial squames, (5) dust cells, (6) bacteria, (7) Curschman's spirals, (8) deoxyribonucleoprotein (D.N.P.) fibres, (9) mucoprotein fibres, and (10) nonfibrous nucleoprotein.

Gross "purulence" was found to vary directly with the total number of cells and the presence of D.N.P. fibres, and the amount of clear gelatinous material varied with the amount of fibrous mucoprotein gel. The proportion of D.N.P. fibres was related to the number of polymorphs that had been present in the preceding specimens rather than to the number in the specimen under examination. Polymorphs were predominant even when the total cell count was low and the sputum consisted mainly of mucoprotein.

The D.N.P. fibres were easily identified by the Feulgen stain, but the Feulgen-negative mucoprotein showed up poorly with the light green counterstain. In ordinary light, mucoprotein could not always be distinguished from the D.N.P. by the other staining methods. Both types of fibre stained blue in aniline blue and orange $G$, and both stained red with the periodic-acid-Schiff, although in the latter the intensity of the D.N.P. staining was less than the mucoprotein. Especially in the presence of autolysis both D.N.P. and mucoprotein fibres tended to stain purple with the pyronin methyl green mixture. A clear differentiation could be obtained using polarized light and a Brace-Köhler compensator of low retardation $(\lambda / 25)$ (Swann and Mitchison, 1950). The fibres were distinguished by the sign of birefringence with respect to fibre length, as listed in Table I. The

TABLE I

THE SIGN OF BIREFRINGENCE IN WHITE LIGHT WITH VARIOUS STAINS

\begin{tabular}{|c|c|c|}
\hline Stain & Mucoprotein & $\begin{array}{c}\text { Deoxyribonucleo- } \\
\text { protein }\end{array}$ \\
\hline $\begin{array}{l}\text { Pyronin-methyl green } \\
\text { Periodic acid-Schiff } \\
\text { Feulgen ... }\end{array}$ & $\begin{array}{l}\text { Positive } \\
\text { No" staining }\end{array}$ & $\begin{array}{l}\text { Negative } \\
\text { Positive }\end{array}$ \\
\hline
\end{tabular}

fuchsin staining of D.N.P. fibres gave positive axial birefringence by the Feulgen method and negative axial birefringence by the periodic-acid-Schiff method, indicating the different modes of attachment of the dye. Metachromatic staining by toluidine blue was not satisfactory for separating the two types of fibre in sputum.

\section{TREATMENT}

The patients were very ill, so the enzyme or control treatment was given in addition to the normal therapy, which consisted of a variety of antibiotics and antispasmodics, and in some cases expectorants and physiotherapy as well. The antispasmodics were omitted for four hours before the estimation of vital capacity or maximal voluntary ventilation.

Each patient was given three inhalations of $3 \mathrm{ml}$. of either enzyme or control solution on the first, third, and fifth days of the period of observation. The control solution consisted of $0.25 \%$ gelatin in $\mathrm{M}-100$ magnesium chloride solution. The enzyme solution was $2.5 \mathrm{mg}$. of ox pancreas deoxyribonuclease dissolved in $3 \mathrm{ml}$. of the control solution. Both were sterilized by Seitz filtration, stored at $5^{\circ} \mathrm{C}$., and used within four weeks of preparation. The control and the enzyme solutions were indistinguishable. Inhalations were given through a "deedon" inhaler modified to run off an oxygen cylinder at 8 to 10 litres a minute through an open-ended T-tube to give an intermittent flow. The nebulized solution was carried to the patient's mouth through a 4-in. perspex tube 


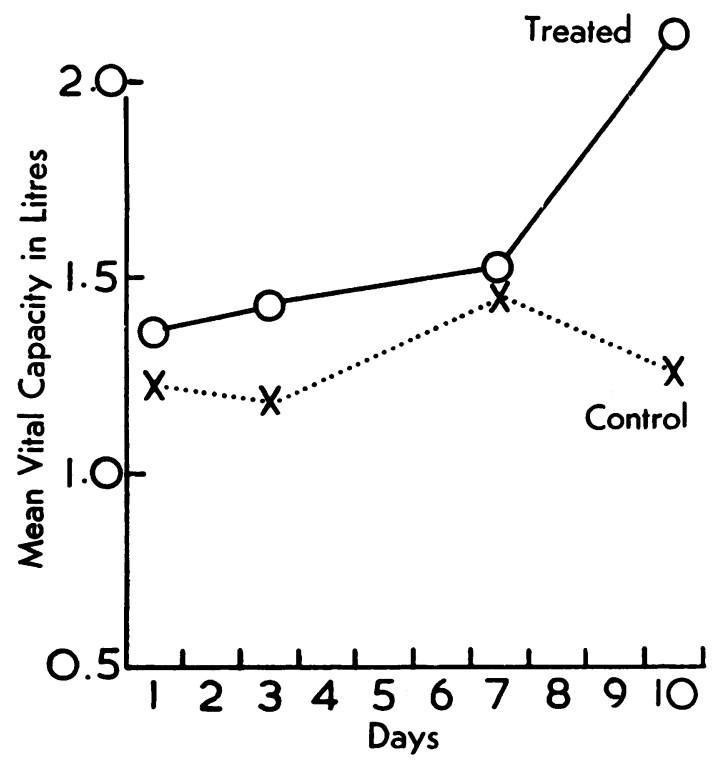

FIG. 2.-The changes in vital capacity during the period of observation. The treated group deviates from the controls only after the treatment is completed. This deviation is not statistically significant.

with an internal diameter of $\frac{3}{4}$ in. $(19 \mathrm{~mm}$.$) ; the$ oxygen flow was turned on during inspiration only. The patient breathed at his accustomed rate and depth ; each treatment took from 10 to 25 minutes. Patients complained of dryness in the throat after enzyme and control treatments. No toxic effects were noted.

The cases were numbered serially and given the solution of corresponding number. The control and enzyme solutions were distributed by random numbers by Dr. D. A. Mitchison.

\section{RESULTS}

Clinical.-The observer was unable to detect which patients received enzyme, and subsequent analysis of clinical progress of the two groups failed to reveal any difference. The changes in vital capacity (Fig. 2) and maximal voluntary ventilation (Fig. 3) showed no significant difference between the two groups. Variations in maximal voluntary ventilation from day to day unrelated to any obvious clinical change suggested that this test is not reliab'e in these ill patients. In case 9 for instance, the maximal voluntary ventilation fell between day 3 and day 7 from 26.6 litres per min. to 16.4 litres per min. in spite of general clinical improvement and a rise in vital capacity from 2 to 2.5 litres. The reason for this appeared to be that the voluntary choice of respiratory rate changes
TABLE II

EFFECT OF RESPIRATORY RATE ON MAXIMAL VOLUNTARY VENTILATION (M.V.V.)

\begin{tabular}{|c|c|c|c|c|c|}
\hline \multirow[b]{2}{*}{$\begin{array}{l}\text { Case } \\
\text { No. }\end{array}$} & \multirow[b]{2}{*}{ Day } & \multicolumn{2}{|c|}{ Lower Respiratory Rate } & \multicolumn{2}{|c|}{ Higher Respiratory Rate } \\
\hline & & $\begin{array}{c}\text { Rate } \\
\text { (breaths } \\
\text { min.) }\end{array}$ & $\begin{array}{l}\text { M.V.V. } \\
\text { (litres' } \\
\text { min.) }\end{array}$ & $\begin{array}{c}\text { Rate } \\
\text { (breaths/ } \\
\text { min.) }\end{array}$ & $\begin{array}{l}\text { M.V.V. } \\
\text { (litres! } \\
\text { min.) }\end{array}$ \\
\hline 12 & $\left\{\begin{array}{l}1 \\
3 \\
7\end{array}\right.$ & $\begin{array}{l}25.0 \\
17.5 \\
10.9\end{array}$ & $\begin{array}{l}5 \cdot 7 \\
6 \cdot 5 \\
6 \cdot 8\end{array}$ & $\begin{array}{l}27.0 \\
21.0 \\
14.4\end{array}$ & $\begin{array}{l}6.4 \\
7 \cdot 1 \\
7 \cdot 9\end{array}$ \\
\hline 19 & $\left\{\begin{array}{r}1 \\
3 \\
10\end{array}\right.$ & $\begin{array}{l}10.6 \\
10.7 \\
10.6\end{array}$ & $\begin{array}{c}10 \cdot 4 \\
7.28 \\
11.6\end{array}$ & $\begin{array}{l}16 \cdot 6 \\
17 \cdot 1 \\
24 \cdot 0\end{array}$ & $\begin{array}{c}9 \cdot 1 \\
8 \cdot 85 \\
11 \cdot 9\end{array}$ \\
\hline 22 & 3 & $19 \cdot 0$ & $14 \cdot 0$ & $60 \cdot 0$ & $20 \cdot 0$ \\
\hline 11 & $\left\{\begin{array}{r}1 \\
7 \\
10\end{array}\right.$ & $\begin{array}{l}16 \cdot 6 \\
11 \cdot 4 \\
19 \cdot 4\end{array}$ & $\begin{array}{l}11 \cdot 5 \\
13 \cdot 2 \\
20 \cdot 7\end{array}$ & $\begin{array}{l}34.8 \\
15 \cdot 8 \\
25.0\end{array}$ & $\begin{array}{l}16 \cdot 3 \\
17 \cdot 9 \\
22 \cdot 7\end{array}$ \\
\hline 14 & $\left\{\begin{array}{l}1 \\
7\end{array}\right.$ & $\begin{array}{l}30.0 \\
25.0\end{array}$ & $\begin{array}{l}17.7 \\
10.1\end{array}$ & $\begin{array}{l}49 \cdot 0 \\
39 \cdot 0\end{array}$ & $\begin{array}{l}17.8 \\
12 \cdot 3\end{array}$ \\
\hline 18 & $\left\{\begin{array}{r}1 \\
3 \\
7 \\
10\end{array}\right.$ & $\begin{array}{r}13.0 \\
12.0 \\
6.0 \\
24.0\end{array}$ & $\begin{array}{r}9.0 \\
9.4 \\
6.0 \\
12.6\end{array}$ & $\begin{array}{l}48.0 \\
36.0 \\
24.0 \\
27.0\end{array}$ & $\begin{array}{l}15.0 \\
14.2 \\
14.2 \\
13.6\end{array}$ \\
\hline 20 & 3 & $32 \cdot 0$ & $7 \cdot 6$ & $46 \cdot 0$ & $8 \cdot 9$ \\
\hline 21 & $\left\{\begin{array}{r}3 \\
10\end{array}\right.$ & $\begin{array}{l}20 \cdot 0 \\
22 \cdot 0\end{array}$ & $\begin{array}{l}10.0 \\
18.0\end{array}$ & $\begin{array}{l}28.0 \\
40.0\end{array}$ & $\begin{array}{l}13.0 \\
18.0\end{array}$ \\
\hline 22 & 7 & $41 \cdot 0$ & $13 \cdot 6$ & $55 \cdot 0$ & $15 \cdot 4$ \\
\hline
\end{tabular}

with the progress of the disease. In subsequent patients readings for maximal ventilatory capacity were obtained at two respiratory rates, one of which was that chosen by the patient. These readings are shown in Table II. In all but two cases the ventilation is greater at the higher rate of respiration. Using these figures the mean value for the ratio

Proportional increase in ventilation

Proportional increase in respiratory rate

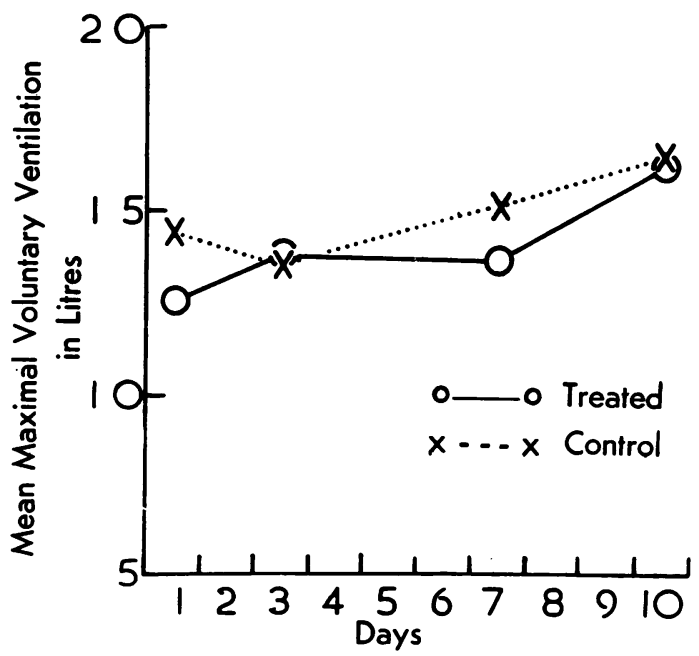

FIG. 3.-The changes in maximal voluntary ventilation during the period of observation. No difference between controls and treated. 
is 0.355 . Applying the $t$ test to this mean, the highly significant value of $P<0.001$ was obtained, indicating that in these patients there is a correlation between a rise in respiratory rate and an increase in ventilation.

Spirometers of the type used are known to give an error in this direction, but at these respiratory rates and small excursion the machine error would not be significant.

In view of the many factors which influence the voluntary respiratory rate in an acute respiratory illness the maximal voluntary ventilation is not a suitable index of progress.

LABORATORY.-The daily volume of sputum and its gross appearance showed no significant difference between the two groups. In some cases the sputum became predominantly mucoid within a day of starting the study, but the majority converted on the fourth or fifth day and a few remained purulent throughout the 10-day period. In some cases the sputum became bright green on being stored at $5^{\circ} \mathrm{C}$. This occurred in 24-hour collections of purulent sputum completed the morning after a treatment either with enzyme or control solution, and was apparently due to a release of verdoperoxidase; it did not occur in all cases.

The cytochemical preparation also showed no difference between the two groups. The changeover from D.N.P. fibres to mucoprotein was not as rapid or clear-cut as the change in the gross appearance. Deoxyribonucleoprotein fibres were never seen without some mucoprotein fibres, whereas by the end of the 10-day period most of the specimens contained only mucoprotein. Occasional early specimens resembled pure pus, were loaded with polymorphonuclear leucocytes, and contained no fibres of either type; subsequent specimens from these cases showed large numbers of D.N.P. fibres and few intact cells.

Viscidity Measurements.-The average yield values obtained with the syringe apparatus are shown in Fig. 4. There is no statistical difference between the two groups as a whole, but the sharp fall in the treated group after the second and third treatments was investigated further. The readings taken before and after each treatment in the two groups are shown in Table III. Expressed in $\log _{10}$ gram units, a mean change in yield value of +0.035 was obtained for the control group and -0.560 for the enzyme group. An analysis of variance gave a value of 0.05 to 0.02 for $P$, indicating a significant difference between the means.

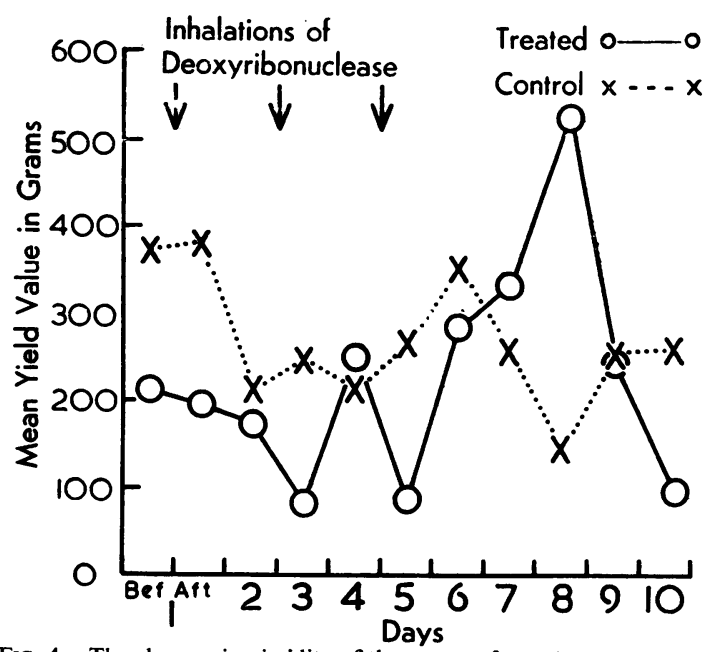

FIG. 4.-The changes in viscidity of the sputum from the two groups measured in arbitrary yield value units. Note the fall in viscidity after the second and third treatments in the enzyme-treated group.

Therefore it is highly probable that treatment with the enzyme caused a reduction in viscidity.

Investigation of individual cases treated with enzyme showed that in some there was a fall in viscidity after each treatment, as in Case 8 (Fig. 5), and in others no response as in Case 19. The cases which respond to treatment have a purulent sputum containing mainly D.N.P. fibres and very few mucoprotein fibres. Those which fail to respond may show some D.N.P. fibres, but there is sufficient mucoprotein to maintain the viscidity of the sputum after the D.N.P. fibres have been

TABLE III

YIELD VALUES IN ARBITRARY GRAM UNITS BEFORE AND AFTER EACH TREATMENT IN CONTROL AND TREATED CASES

\begin{tabular}{|c|c|c|c|c|c|}
\hline \multicolumn{3}{|c|}{ Control Series } & \multicolumn{3}{|c|}{ Treated Series } \\
\hline Case No. & Before & After & Case No. & Before & After \\
\hline $10\left\{\begin{array}{l}1 \\
2 \\
3\end{array}\right.$ & $\begin{array}{l}375 \\
375 \\
225\end{array}$ & $\begin{array}{l}375 \\
325 \\
225\end{array}$ & $8\left\{\begin{array}{l}1 \\
2 \\
3\end{array}\right.$ & $\begin{array}{l}110 \\
190 \\
210\end{array}$ & $\begin{array}{r}0 \\
10 \\
110\end{array}$ \\
\hline $11\left\{\begin{array}{l}1 \\
2 \\
3\end{array}\right.$ & $\begin{array}{l}900 \\
450 \\
450\end{array}$ & $\begin{array}{l}600 \\
450 \\
500\end{array}$ & $9\left\{\begin{array}{l}1 \\
2 \\
3\end{array}\right.$ & $\begin{array}{r}125 \\
75 \\
125\end{array}$ & $\begin{array}{r}40 \\
140 \\
40\end{array}$ \\
\hline $14\left\{\begin{array}{l}1 \\
2 \\
3\end{array}\right.$ & $\begin{array}{r}40 \\
80 \\
160\end{array}$ & $\begin{array}{l}140 \\
140 \\
380\end{array}$ & $12\left\{\begin{array}{l}1 \\
2\end{array}\right.$ & $\begin{array}{r}60 \\
250 \\
20\end{array}$ & $\begin{array}{l}10 \\
10 \\
20\end{array}$ \\
\hline $17\left\{\begin{array}{l}2 \\
3\end{array}\right.$ & $\begin{array}{r}100 \\
40\end{array}$ & $\begin{array}{r}60 \\
140\end{array}$ & $16\left\{\begin{array}{l}1 \\
2 \\
3\end{array}\right.$ & $\begin{array}{l}20 \\
10 \\
20\end{array}$ & $\begin{array}{r}20 \\
10 \\
0\end{array}$ \\
\hline $18\left\{\begin{array}{l}1 \\
2 \\
3\end{array}\right.$ & $\begin{array}{l}500 \\
120 \\
300\end{array}$ & $\begin{array}{l}700 \\
150 \\
300\end{array}$ & & $\begin{array}{l}350 \\
250\end{array}$ & $\begin{array}{l}800 \\
200\end{array}$ \\
\hline $21\left\{\begin{array}{l}1 \\
2 \\
3\end{array}\right.$ & $\begin{array}{r}300 \\
80 \\
120\end{array}$ & $\begin{array}{r}230 \\
300 \\
70\end{array}$ & 221 & 600 & 300 \\
\hline $23\left\{\begin{array}{l}1 \\
2\end{array}\right.$ & $\begin{array}{l}300 \\
300\end{array}$ & $\begin{array}{l}250 \\
300\end{array}$ & & & \\
\hline
\end{tabular}


destroyed. Purulent sputum was usually less viscid than mucoid.

Three sequences of viscosity changes were observed and are illustrated by Fig. 5. (1) In Case 14 the viscidity is low initially when D.N.P. fibres predominate. The gross proportion of mucoid to purulent changes from $1: 2$ on the third day to $5: 1$ on the sixth while the viscidity rises. This patient received inhalations of control solution. (2) Case 8 produced purulent sputum at first but was producing quantities too small for viscidity measurements after the sixth day. The initial viscidity is low and falls with each enzyme treatment, rising afterwards to progressively higher levels as the proportion of mucoprotein fibres increases. (3) Case 19 was converting to predominantly mucoid sputum at the beginning of the study. Initial viscidity readings are high and fall gradually; treatment with enzyme had no

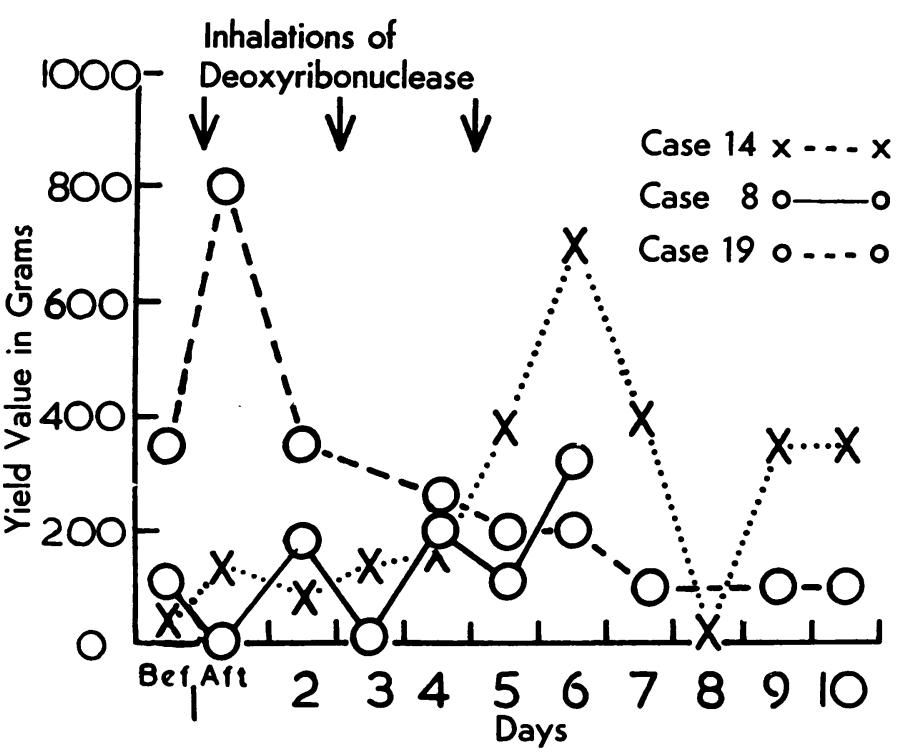

FIG. 5.-The changes in viscidity of the sputum in individual cases. Case 14 started with purulent sputum, became predominantly mucoid at day 5 and received control solution. Case 8 had purulent sputum and received enzyme; note the fall in viscidity after each treatment. Case 19 was converting to mucoid at the beginning of the study and treatment with enzyme had no effect. effect.

The effect of the enzymes as measured by the viscidity does not appear to last more than 12 hours, and some D.N.P. fibres remained in the specimens collected during the 12 hours following the first treatment. This may be due to failure of the enzyme to diffuse into the more viscid masses, especially in the presence of mucoprotein gel, which is unaffected by the enzyme.

This study has shown that the following changes occur in the sputum during an exacerbation of chronic bronchitis. In the interval between acute episodes the sputum is scanty, clear and gelatinous. Its viscidity is moderately high and cytochemical examination shows few cells, both polymorphs and mononuclears being present. The viscidity is due to a fibrous gel of mucoprotein. During the onset of an exacerbation the volume increases and viscidity falls. It becomes turbid and yellow due to the presence of large numbers of polymorphs, the relative proportion of mucoprotein falls. The polymorphs disintegrate, forming fibres of D.N.P. which are temporarily responsible for the viscidity of the secretion. Finally, the proportion of mucoprotein gradually increases as the cells and D.N.P. fibres disappear, until the secretion is indistinguishable cytochemically from that in the interval phase. At this stage the viscidity is greatest and the daily volume high. Both gradually fall to the interval state.

The time taken for these changes varies greatly in patients who receive no antibiotic, but those who are treated with an effective antibiotic usually reach the pure mucoid phase by the fourth or fifth day. The duration of the phase of excessive secretion of mucoid material is variable even with treatment. If D.N.P. fibres become sufficiently numerous to be the main cause of the viscidity, this is usually only on the second and third day in the treated cases, but may last for over a week in untreated cases.

Curschman's spirals were present in more than half the cases, though usually in small numbers. They were seldom seen when large numbers of polymorphs were present and were never seen in the absence of mucoprotein. They had the same staining properties as mucoprotein, the same sign of birefringence, and the ends of the spirals usually fanned out into fibres which were continuous with the surrounding network of mucoprotein. The spirals often contained particles of opaque or birefringent particulate material and sometimes fibrous deoxyribonucleoprotein. Their presence was not obviously related to any clinical or pathological stage in the disease.

\section{Discussion}

These results do not permit any final conclusion to be drawn as to the efficiency of pure deoxyribonuclease in the treatment of purulent bronchitis. 
They indicate that the enzyme is capable of liquefying purulent sputum, but that its effect lasts for less than 12 hours in the doses used. The treatment in this series was inadequate, and the absence of any demonstrable clinical response is to be expected.

The majority of cases of bronchitis admitted to hospital during an exacerbation are producing sputum whose viscidity is mainly due to mucoprotein. If the purulent phase is very marked the viscidity at that time is relatively low, and with modern antibiotics correctly used this phase is brief. A more adequate trial of deoxyribonuclease has been deferred therefore until its use can be combined with an enzyme which causes specific liquefaction of respiratory mucus.

Commercial streptococcal enzyme preparations contain a deoxyribonuclease and a fibrinolysin. They are effective in the liquefaction of exudates in closed cavities, but are ineffective against respiratory mucus. Their deoxyribonuclease content is relatively low and they have not been widely used for the treatment of purulent bronchitis. Nonspecific mucolytic enzymes are already available, and owing to proteolytic activity they will reduce the viscosity of mucus in solution (Limber, Reiser, Roettig, and Curtis, 1952). Although these and other authors publish encouraging impressions (Steigman and Scott, 1952), in vitro testing of the enzyme on whole respiratory mucus indicates very little effect.

The use of deoxyribonuclease and commercial trypsin causes no untoward effects. The function of mucus in respiratory secretion is generally considered to be protective ; if completely removed by an enzyme it might expose the mucosa to bacterial invasion or other damage. The mode of action of the mucus is obscure and some of its properties not entirely beneficial. For instance its presence is essential for the invasion of the respiratory mucosa by the influenza virus in mice (St. Groth, 1948), but it may contain high concentrations of antibodies specific against bacteria and viruses. Whether these would be inactivated by enzyme treatment remains to be determined.

\section{SUMMARY}

Inhalations of pure beef pancreas deoxyribonuclease have been used in the treatment of patients with acute purulent exacerbations of chronic bronchitis.

The enzyme reduces the viscidity of the purulent sputum, but has no effect on mucoid sputum.

No objective change in the clinical course of the disease was noted, and cytochemical investigations suggest that the dosage was inadequate.

The serial changes in the sputum during such exacerbations are described, and the importance of excessive mucous secretion emphasized.

The need for investigation of specific mucolytic enzymes is discussed.

We wish to thank the physicians of Hammersmith Hospital for allowing us to study and treat their patients, and the nursing staff for collecting the specimens. We would like to acknowledge the help and encouragement of Professor J. W. Crofton in the design of this study, Dr. D. A. Mitchison in the statistical analysis, and Dr. J. G. Scadding in the preparation of the material for publication.

\section{REFERENCES}

Armstrong, J. B., and White, J. C. (1950). Lancet, 2, 739.

Brachet, J. (1942). Arch. Biol., Paris, 53, 207.

Elmes, P. C., and White, J. C. (1953). Proceedings of 2nd Int. Congress of Rheology, Oxford.

Feulgen, R, and Rossenbeck, H. (1924).Hoppe-Seyl. $Z, 135,203$. Hotchkiss, R. D. (1946) See Glick, D., Techniques of Histo- and Cytochemistry, pp. 44-5. Interscience, New York, 1949 .
otchkis, R.

Limber, C. R., Reiser, H. G., Roettig, L. C., and Curtis, G. M. (1952). J. Amer. med. Ass., 149, 816.

Lucas, G. H. W., and Henderson, V. E. (1936). Arch. int. Pharmacodyn., 54, 201

St. Groth, S. F. de (1948). Aust. J. exp. Biol. med. Sci., 26, 29.

Steigman, A. J., and Scott, C. H. (1952). J. Amer. med. Ass., 150 , 1403 .

Swann, M. M., and Mitchison, J. M. (1950). J. exp. Biol., 27, 226. White, J. C. (1950). Biochem. J., 46, xxiv. 